Anuário do Instituto de Geociências - UFRJ

FORAMS 2006

\title{
The coiling direction paradox in Neogloboquadrina pachyderma
}

\author{
Kate Darling ${ }^{1}$; Michal Kucera ${ }^{2}$ \& Chris Wade ${ }^{3}$ \\ ${ }^{1}$ Grant Institute of Earth Science/Institute of Evolutionary Biology, University of Edinburgh, \\ Edinburgh, U.K. Kate.Darling@ed.ac.uk \\ ${ }^{2}$ Institut für Geowissenschaften, Eberhard-Karls Universität Tübingen, Tübingen, Germany \\ ${ }^{3}$ Institute of Genetics, University of Nottingham, Nottingham, U.K.
}

Planktonic foraminifera with trochospirally arranged chambers can produce shells with two different coiling directions. Some morphospecies show a strong preference for either right-handed (dextral) or left-handed (sinistral) coiling, while other morphospecies appear in mixed coiling proportions varying around a midpoint value. Some display a pattern of distinct shifts in their coiling ratios spatially and through time. Although the underlying mechanisms controlling coiling direction are not understood, many workers have assumed it to be a morphological feature reflecting ecophenotypic variation and have used coiling ratios extensively for paleoenvironmental reconstruction. Recent genetic studies now clearly demonstrate that coiling direction in planktonic foraminifera is a genetic trait, heritable through time and not environmentally controlled. Previously reported links between coiling and environmental factors result from the different ecological preferences of the genetically distinct coiling types.

Neogloboquadrina pachyderma is the most important provider of paleoproxies on the state and variation of high latitude oceans in the Quaternary. It has two distinct coiling forms with virtually exclusive distributions that appear to be controlled by water temperature. The genetic evidence shows that the two opposite coiling morphotypes diverged many millions of years ago and they have distinctly different ecologies. In combination with fossil evidence, biogeography and ecology, the degree of genetic distinction between the two coiling types of $N$. pachyderma strongly implies that they should be considered different species. The genetic evidence also demonstrates a low level $(<3 \%)$ aberrant coiling associated with each morphotype posing a serious nomenclature problem for taxonomists and paleoceanographers alike. The presence of aberrant coiling and the continual need for paleoceanographers to refer to coiling direction in the literature demands the re-classification of the right coiling $N$. pachyderma genotypes as a distinct species to simplify nomenclature and reference. We propose the adoption of the widely recognized name incompta for the dextral morphospecies. 